\title{
ESTÁGIO DO CURSO DE ESPECIALIZAÇÃO EM SAÚDE MENTAL: RELATO DE EXPERIÊNCIA EM UM CAPS
}

\author{
Maria de Lourdes Custódio Duarte ${ }^{1}$, Leandro Barbosa de Pinho², Adriana Inocenti Miasso ${ }^{3}$
}

\begin{abstract}
RESUMO: O presente estudo relata a experiência em seu estágio obrigatório para o título de especialista em Enfermagem em Saúde Mental vinculado ao programa de pós-graduação da Universidade de São Paulo. O estágio foi desenvolvido em um Centro de Atenção Psicossocial da Região Sul do Brasil nos meses de junho e julho de 2006. Os Centros de Atenção Psicossocial têm feito a sua parte enquanto um lugar de reabilitação psicossocial para os usuários e um lugar de formação de estudantes. Foram evidenciados limitações e potencialidades do serviço enquanto um dispositivo importante na rede de atenção psicossocial. A experiência do estágio foi de grande valia para a estudante, usuários e equipe de saúde, pois todos puderam usufruir das trocas geradas nesse encontro.
\end{abstract}

PALAVRAS-CHAVE: Saúde mental; Enfermagem psiquiátrica; Ensino.

\section{AN INTERNSHIP IN A MENTAL HEALTH SPECIALIZATION COURSE: AN ACCOUNT OF EXPERIENCE IN A CENTER FOR PSYCHO-SOCIAL ATTENTION}

ABSTRACT: This study relates the experience of an internship, mandatory for the title of Specialist in Mental Health Nursing, linked with the post-graduate program of the University of Sao Paulo. The internship was carried out in a Center for Psycho-Social Attention in South Brazil, in the months of June and July 2006. The Centers for Psycho-Social Attention have played their part both as places for the rehabilitation of health service users and as places for the training of students. Evidence was found for both the limitations and potential of the service as an important tool in the psycho-social attention network. The experience of the internship was of great value to the student, health service users and the health team, as all were able to benefit from the exchanges brought about by this encounter.

KEYWORDS: Mental Health; Psychiatric Nursing; Teaching.

\section{PRÁCTICAS DEL CURSO DE POSGRADO EN SALUD MENTAL: INFORME DE EXPERIENCIA EN UN CAPS}

RESUMEN: Este estudio relata la experiencia en las prácticas obligatorias para la titulación de especialista en Enfermería en Salud Mental asociado al programa de posgrado de la Universidad de São Paulo. Las prácticas fueron desarrolladas en un Centro de Atención Psicosocial de la Región Sur de Brasil en los meses de junio y julio de 2006. Los Centros de Atención Psicosocial cumplieron su función de lugar de rehabilitación psicosocial para los usuarios, así como la función de formar estudiantes. Fueron evidenciadas limitaciones y potencialidades del servicio como mecanismo importante en la red de atención psicosocial. La experiencia de las prácticas fue muy importante para el estudiante, usuarios y equipo de salud, pues a todos fue posible disfrutar de los cambios generados en ese encuentro.

PALABRAS-CLAVE: Salud mental; Enfermería psiquiátrica; Enseñanza.

1Enfermeira. Mestre em Enfermagem Psiquiátrica. Doutoranda em Enfermagem pelo Programa de Pós-Graduação em Enfermagem da Universidade Federal do Rio Grande do Sul - UFRGS. Professora da Universidade Federal do Pampa-UNIPAMPA.

${ }^{2}$ Enfermeiro. Doutor em Enfermagem Psiquiátrica. Professor da Escola de Enfermagem e do Programa de Pós-Graduação da UFRGS.

${ }^{3}$ Enfermeira. Doutora em Enfermagem Psiquiátrica. Professora da Escola de Enfermagem e do Enfermagem e do Programa de Pós-Graduação de Ribeirão Preto da Universidade de São Paulo.

Universidade Federal do Pampa

Rua Gonçalves Ledo, 20 - 90610-250 - Porto Alegre-RS-Brasil

E-mail:malulcd@yahoo.com.br 


\section{INTRODUÇÃO}

No paradigma de atendimento preconizado pela Reforma Psiquiátrica, procura-se a reintegração social do portador de transtornos mentais através do auxílio da família e de sua integração com a rede de serviços. Trata-se de uma nova maneira de enxergar a loucura, trabalhando com dispositivos que possam superar tratamentos tradicionais considerados segregatórios, tutelares, baseados na autoridade e no isolamento.

O movimento da Reforma Psiquiátrica, iniciado na década de 1970, pode ser entendido como um amplo e intenso movimento de contestação à ciência psiquiátrica, que transcende a busca por soluções exclusivamente técnicas ou administrativas, e trabalha com questões complexas no campo político, jurídico, social e cultural. Nesse cenário, a desinstitucionalização dos sujeitos com transtornos mentais tornou-se uma luta contra todo o histórico violento que insistia no manicômio como única abordagem terapêutica ${ }^{(1)}$. A necessidade de romper com posturas semelhantes, autoritárias e excludentes, possibilitou analisar o sujeito a partir das múltiplas dimensões que fazem parte de sua vida, buscando o equilíbrio biológico, psicológico, social, cultural e espiritual ${ }^{(2)}$.

Percebemos, atualmente, que essas transformações vêm exigindo não somente a reestruturação de serviços de saúde, mas também a adequação do cardápio de competências e habilidades do profissional de saúde, seja essa formação de graduação ou de pós-graduação. Isso, por sua vez, caracteriza uma nova dimensão a ser explorada e melhor compreendida pela sociedade, pois se trata da materialização de experiências de aprendizado que podem produzir mudanças na oferta de ações de cuidado e na realidade social onde estão inseridos os indivíduos $^{(3-4)}$. É nesse cenário que podemos situar a participação dos Centros de Atenção Psicossocial (CAPS) como dispositivos estratégicos do processo de reforma psiquiátrica e como um novo campo de práticas dos profissionais da saúde.

Assim, o presente estudo tem como objetivo relatar a experiência de uma enfermeira em um estágio curricular do Curso de Especialização em Saúde Mental, oferecido pela Escola de Enfermagem de Ribeirão Preto. Orientado pelas premissas do modelo psicossocial, o estágio foi realizado em um CAPS da Região Sul do Brasil.

\section{CONTEXTUALIZAÇÃO DO CURSO DE ESPE- CIALIZAÇÃO EM SAÚDE MENTAL}

O Curso de Especialização em Saúde Mental tem o objetivo de capacitar enfermeiros e outros profissionais da Psiquiatria e da Saúde Mental no aprofundamento de conhecimentos da área, desenvolvendo habilidades e atitudes pertinentes ao exercício da especialidade. Com duração de um ano, disponibiliza 26 vagas anuais, ocorrendo todas as sextas-feiras (das 8 às 18 horas) e todos os sábados (das 9 às 12 horas), possuindo um total de 450 horas, das quais 240 horas são de aulas teóricas e 210 são destinados ao estágio. A partir do estágio, o aluno deve fazer um relatório das atividades desenvolvidas no campo de estágio e tecer propostas de melhorias do serviço.

Compactuando com as transformações da atenção em saúde mental, o Curso tem priorizado desenvolver os estágios em serviços substitutivos ao hospital psiquiátrico, destacando aqueles que vêm compondo a Rede de Atenção em Saúde Mental ${ }^{(5)}$ : Atenção Básica, Centros de Atenção Psicossocial (CAPS), ambulatórios especializados, hospital-dia, urgência e emergência psiquiátricas, leitos em hospital geral e serviços residenciais terapêuticos.

A escolha dos serviços substitutivos ao modelo manicomial se apoia na oferta de ações de cuidado inclusivas, orientadas pelas premissas da reabilitação psicossocial do indivíduo em sofrimento mental ${ }^{(6)}$. Apesar disso, devido à existência de muitos serviços tradicionais na realidade brasileira, e pensando na necessidade de problematizar o processo de consolidação da Reforma, o Curso oferece uma visita a um hospital psiquiátrico.

\section{A EXPERIÊNCIA DO ESTÁGIO NO CAPS}

O CAPS II, local do estágio, foi fundado em 1996 sendo implementado como um serviço substitutivo ao hospital psiquiátrico, tendo por objetivo principal evitar internações psiquiátricas, recorrentes ou não, possibilitando o acompanhamento na urgência psiquiátrica, bem como viabilizando a reabilitação e inserção social do sujeito em sofrimento psíquico. É um serviço vinculado à rede de atenção em saúde mental de um município da Região Sul do Brasil.

Esse serviço funciona das 8 hs às 18 horas e está localizado em um casarão antigo da cidade. Conta com um espaço físico de 22 ambientes e com uma equipe multidisciplinar composta por 23 profissionais, além 
de 20 estagiários dos cursos de Terapia Ocupacional, Enfermagem e Psicologia e dos mais diversos cursos de graduação e pós-graduação (especialização e residências), servindo de um ambiente propício para o aprendizado e formação de futuros profissionais.

O serviço possui as seguintes modalidades de atendimento: Regime Intensivo, Semi-Intensivo e o Não Intensivo. O Regime Intensivo é destinado a usuários em situação de crise, passam o dia no serviço, recebem alimentação e são atendidos individualmente e/ou em grupos e oficinas. O Regime Semi-Intensivo é destinado a usuários cujo grau de organização permite com que possam participar de atividades agendadas segundo plano terapêutico. Já o Regime Não Intensivo integra os usuários que necessitam de atendimento interdisciplinar continuado e cujo grau de autonomia já permite o desenvolvimento de atividades fora do serviço ${ }^{(7)}$.

O número de vagas disponíveis para atendimento está assim dividido: 10 vagas para regime intensivo, 30 vagas para regime semi-intensivo e 280 para o regime não-intensivo (ambulatório). Numa primeira análise, verificamos que o serviço encontrava-se com sua lotação máxima, ou seja, com 40 usuários no sistema semi-intensivo e com 280 usuários no regime não-intensivo ${ }^{(7)}$.

As reuniões em equipe ocorrem em dois dias da semana. Em uma reunião toda equipe se reúne para discutir alguns casos de pacientes, problemas administrativos, comunicações entre profissionais, de familiares com equipe e também sobre o processo de alta; já em outra, são discutidos todos os casos de usuários que se encontram no Regime Intensivo e outros casos que, por ventura, têm necessidade de utilizá-lo.

Algumas atividades são desenvolvidas no CAPS com a finalidade de viabilizar que o usuário encontre um espaço onde possa se reconhecer e ser conhecido; essas atividades são chamadas de "Convívio" e, dentre elas, podemos destacar: Hora do Chá, Notícias do Dia e Assembléia dos Usuários.

Salientamos a Assembléia dos Usuários como um importante espaço para a discussão de assuntos de interesse desses sujeitos, além de ser um espaço privilegiado para que equipe e usuários possam fazer, juntos avaliação do andamento do serviço, além de discutir e viabilizar mecanismos que venham a enriquecer e facilitar o funcionamento da instituição. Durante o estágio foi constatado que os usuários organizam-se no decorrer da semana preparando a pauta de assuntos da Assembleia; muitas vezes suas reivindicações são relacionadas à falta de material para oficinas ou até mesmo relacionadas às refeições e alimentos disponibilizados pelo CAPS.

Algumas ações intersetoriais são desenvolvidas no cotidiano do CAPS, dentre elas o "Projeto Insere", que objetiva firmar parcerias com a comunidade em geral. Trata-se de um projeto que visa a obter oportunidades de inclusão social aos usuários dos serviços de saúde mental do município, nas áreas de Cultura, da Educação, do Esporte e do Lazer, bem como a obtenção de vagas em cursos profissionalizantes.

Há também o desenvolvimento de oficinas temáticas e de geração de renda, que podem ser consideradas como excelentes recursos terapêuticos ${ }^{(8)}$, e a indicação para participar depende do plano terapêutico traçado para cada usuário e do interesse dos mesmos em realizá-las. Nessa modalidade, registrou-se as oficinas de jornal, teatro, terapia ocupacional e grupos de conversas. Todas as atividades desenvolvidas no serviço constam em um cronograma semanal para que os usuários possam se organizar e participar.

\section{LIMITAÇÕES E POTENCIALIDADESDOSERVIÇO}

Durante o estágio, a aluna do Curso de Especialização teve a oportunidade de vivenciar o cotidiano do CAPS, bem como inserir-se nas diversas atividades do serviço. A partir dessa experiência, foi possível elencar algumas limitações e potencialidades do CAPS.

As limitações e fragilidades foram percebidas e vivenciadas pela aluna no dia-a-dia do estágio. Dentre elas podemos citar: escasso recurso financeiro, o que influenciava diretamente na aquisição de material para as oficinas e grupos, e a pequena infraestrutura da área física, que carecia de reformas específicas, principalmente no que diz respeito ao manejo das crises.

Também foi possível perceber que o serviço apresenta um grande número de usuários que frequentam regularmente o serviço. A superlotação do serviço foi explicada, pelos próprios profissionais, a partir de dois motivos principais: o número de altas é pequeno, e a equipe justifica isso em função da forte relação com os próprios usuários do serviço. Além disso, a equipe parece temer recaídas, o que também limita o número de altas.

Dessa forma, considera-se que o número restrito de altas traz prejuízos para o processo de trabalho da equipe. Na medida em que não há altas, a tendência é que haja "inchamento" do serviço, o que estimula muito mais o processo de cronificação da loucura do que sua própria superação. Já há autores discutindo o tema ${ }^{(2,9-}$ ${ }^{10)}$. Faz-se necessário, pois, encontrar estratégias para 
problematizar, continuamente, o cotidiano do processo de trabalho junto com a equipe.

Outra limitação observada pela aluna foi relacionada à pouca participação das famílias dos usuários no serviço. O CAPS oferece um grupo de suporte, pois acredita que é importante prestar acompanhamento e esclarecimentos ao grupo familiar, e desenvolve atividades de orientação, compartilhando dúvidas, anseios e necessidades de cada familiar. Ao mesmo tempo, a equipe vem enfrentando dificuldades na adesão das famílias à proposta, pois, até o final do estágio, já haviam ocorrido três tentativas de formação desse grupo, sem sucesso.

No entanto, várias potencialidades foram evidenciadas pela estagiária, dentre elas pode-se citar: o trabalho em equipe interdisciplinar; o vínculo estabelecido entre profissionais e usuários; as ações intersetoriais formando parcerias importantes (universidades, faculdades, albergues, residenciais terapêuticos) para o serviço; e a responsabilidade do CAPS em servir como campo de estágio (graduação e pós-graduação), propiciando a formação de futuros profissionais.

No contexto das potencialidades do serviço, a parceria ensino-serviço pode ser entendida como recurso para o processo de consolidação da Reforma Psiquiátrica e também para a ressignificação da loucura. Desta forma, o CAPS torna-se um espaço de integração ensino-serviço e um cenário privilegiado na formação dos profissionais da área de Saúde Mental.

A presença da aluna do Curso de Especialização no serviço representava um suporte no atendimento em saúde mental, facilitando alguns encaminhamentos e servindo como uma pessoa disponível às necessidades dos usuários. O diálogo e a escuta, além dos conhecimentos da própria profissão - Enfermagem - foram ferramentas importantes utilizadas pela estagiária no serviço.

\section{CONSIDERAÇÕES FINAIS}

A oportunidade de realizar estágio em serviços substitutivos aos manicômios proporciona ao aluno construir um novo conceito acerca da loucura, valorizando os aspectos sociais, culturais, políticos e econômicos relacionados ao modelo psicossocial de assitência. Além disso, existe a intenção de focalizar a formação dos profissionais especializados para atuar de acordo com os pressupostos das atuais políticas de Saúde Mental no Brasil, orientada para o modelo extra-hospitalar.

Apesar das dificuldades enfrentadas no cotidiano do processo de trabalho, o serviço vem possibilitando a oferta de ações inclusivas e que estimulem as parcerias intersetoriais, especialmente a parceria ensino-serviço de saúde. A participação dos estudantes em serviços constituídos sob a lógica do novo modelo pode ser entendida como um dos aspectos que reorienta a formação, além de ser um cenário de compreensão e oferta de ações de cuidado articuladas com as reais necessidades da vida cotidiana dos usuários.

Finalizando, a experiência como estagiária, aluna de um Curso de Especialização, foi positiva, integrando diferentes profissionais na troca de saberes e proporcionando um (re) pensar sobre as práticas desenvolvidas nos serviços de Saúde Mental.

\section{REFERÊNCIAS}

1. Elsen I, Waidman MAP. Os caminhos para cuidar da família no paradigma da desistitucionalização: da utopia a realidade. Ciênc Cuid Saúde. 2005;5 Suppl:S107-12.

2. Amarante PDC. Loucos pela vida: a trajetória da reforma psiquiátrica no Brasil. $3^{\mathrm{a}}$ ed. Rio de Janeiro: Fiocruz; 2005.

3. Olschowski A. O ensino de enfermagem psiquiátrica e saúde mental: analise da pós-graduação "Lato Sensu" [tese]. São Paulo (SP): Universidade de São Paulo; 2001.

4. Barros S, Lucchese R. Problematizando o processo ensino-aprendizagem em enfermagem em saúde mental. Trab Educ Saúde. 2006;4(2):337-53.

5. Ministério da Saúde(BR). Guia de saúde mental. Governo do Estado do Rio Grande do Sul. Porto Alegre; 2001.

6. Delfine PSS, Sato MT, Antoneli PP, Guimarães POS. Parceria entre CAPS e PSF: o desafio da construção de um novo saber. Rev C S Col. 2009;14 Suppl 1:S1483-92.

7. Secretaria Municipal de Saúde. Planejamento Estratégico. Cais Mental Centro: Centro de Atenção Psicossocial. Porto Alegre (RS): SMS; 2003.

8. Milke FB, Olschowsky A. A experiência do estágio de docência. Cogitare Enferm. 2009;14(3):579-83.

9. Wetzel C. Avaliação de serviços em saúde mental: a construção de um processo participativo [tese]. Ribeirão Preto (SP): Universidade de São Paulo; 2005.

10. Pinho LB. Análise crítico-discursiva da prática de profissionais de saúde mental no contexto social da reforma psiquiátrica [tese]. Ribeirão Preto (SP): Universidade de São Paulo; 2009. 